\title{
Skipping Breakfast Everyday Keeps Well-being Away
}

AK Mohiuddin ${ }^{1, *},[\mathrm{MD}]$
ORCID: 0000-0003-1596-9757

1 Department of Pharmacy, World University of Bangladesh, Bangladesh

* Corresponding Author: AK Mohiuddin, e-mail: trymohi@gmail.com, +8801716477485

DOI:10.32552/2019.ActaMedica.341
neO ABSTRACT Ceen

Breakfast, the first meal of the day, is considered the most important meal throughout the day. As nutritionist Adelle Davis famously put it back in the 1960s: "Eat breakfast like a king, lunch like a prince and dinner like a pauper". Breakfast is most commonly skipped meal more than lunch and dinner specifically in the young adult in the university study period and those who wake up late. Lack of time is the main reason behind skipping meals, in general, lack of appetite, inability to cook, fasting/religion, and not being hungry. Many people are used to be in a hurry for job, business, children's' school in the morning where a filled stomach may prevent them to walk a long way. It is obvious that the irregular omission of breakfast may be effective in energy intake reduction over the next 24 hours and in this day, exercise performance may be compromised. There is no evidence that breakfast skipping reduces overeating or prevent weight gain. Some people argue that breakfast and good health is a marketing strategy by breakfast companies.

Keywords: Breakfast, meal, appetite, omission, energy, metabolism, time, fasting, skipping meal.

\section{INTRODUCTION}

The simple definition of breakfast is "the first meal of the day," which is consistent with the etymology to "break" the "fast."It is simply identified as "the first meal of the day, consumed within 2 hours of waking, before starting daily activities. Experts say that people who eat breakfast are less likely to overeat the rest of the day. Breakfast-eaters tend to have lower rates of heart disease, high blood pressure and high cholesterol, the American Heart Association reported in 2017. It might be better for weight loss to skip dinner, even eating an early dinner can boost calorie burn, according to Times Magazine. Moreover, it is found that Japanese people has decreased energy intake but the percentage of obese people has increased. This suggests that the timing of meals is related to obesity. However, skipping meals has become an increasingly popular part of modern life, especially in young adults. It was found that irregular omission of breakfast might be effective in energy intake reduction over the next 24 hours if the breakfast is habitually consumed and, in this day, exercise performance may be compromised. Cardiac function and sugar control mechanism disrupted along with wait gain, declined wits, mood swing, lethargy, bad breath, low cortisol, chronic inflammation, worsen periods in women commonly reported.

\section{Skipping Breakfast: An Unhealthy Approach}

Unhealthy dietary behaviors play crucial role in increasing the upcoming risk of chronic diseases [1]. Breakfast is recommended to contain $20 \%-35 \%$ of daily energy needs [2]. It is considered the most important meal of the day as a part of a healthy balanced diet [3]. Breakfast habits are significantly associated with physiological, psychological, and social health dimensions [4]. Several studies reported associations between breakfast skipping and fatigue at noon, worsens memory and higher body mass index as well as increased prevalence of obesity-related chronic illness [5-7]; deficient in total energy, vitamins and minerals [8], increased risk of central adiposity [9], and risk of insulin resistance and cardio-metabolic disorders [10]. If the stomach is 
kept empty for a long time, the body will suffer a deficiency of proteins and glucose. Then blood sugar will drop down followed by mood swing [11]. In an Italian population-based study, there is a positive association between headache and meal skipping, especially due to the irregular intake of breakfast [12]. Breakfast is often described as the most important meal of the day, providing as it does sustenance and energy (i.e., calories) for whatever activities lay ahead [13]. Some studies have used solid foods only as breakfast and neglected other highly calorific beverages available, even with the fact that there are "differences in gastric emptying rate and metabolic response to different nutrients in solid versus liquid form" [14].

\section{"Breakfast" Interpretation in Life Science}

A calorie is a balance of net energy does not differentiate between ingested nutrients or calories regarding chewing or not. By definition, it is the amount of heat required to raise the temperature of one gram of water from $14.5^{\circ} \mathrm{C}$ to $15.5^{\circ} \mathrm{C}$. 1 calorie $=$ 4.184 joules. An amount of $209.2 \mathrm{~kJ}$ (50 kcal) is an appropriate starting spot to dismiss common behaviors that would not be recognized as a meal by most of the people. On the other hand, "time of day, time of waking, and/or the intervals that differentiate separate eating occasions" are also important considerations. [15]. A duration of 2 hours after waking up was used in the definition of the breakfast meal and has been differentiated from snacks by a cut-off point of $1,087.8 \mathrm{~kJ}(260 \mathrm{kcal})$ and independent consumption cases secluded on the basis of a $45 \mathrm{~min}$ utes period [16,17]. Generally, it is sensible for an operational definition of breakfast to exemplify as "the first meal consumed within 2 hours after prolonged sleep in any 24 hours duration," which represents the extended daily time consumed in the fasted-situation and the only time when most of the people are really post-absorptive $[17,18]$.

\section{A Common Issue of Breakfast Skipping with Young Adulthood}

Meal skipping rates may be highest during young adulthood, a period of transition and development [19]. Silliman et al. and Sakamaki et al. reported a high prevalence of meal skipping among young adult population ranged from $24 \%$ to $87 \%$ [20], [21]. Several studies reported that recurrent missed breakfast among different age groups was more than lunch and dinner. Among the sample of
Americans from different ages, the rate of breakfast skipping was nearly $11 \%$ comparing with lunch skipping around $10 \%$ and dinner skipping more than 5\% $[22,23]$. Another study among college students at the University of North Carolina, Charlotte reported that almost half (44.2\%) of the students never take their breakfast comparing with lunch (3.5\%) and dinner (2.3\%) [24]. Australian young adults reported eating breakfast less than 5 days per week, compared with $10 \%$ of children and $33 \%$ of all adults (>18 years) [25].

\section{Reasons Behind Breakfast Skipping}

Afolabi et al. reported that $48 \%, 19 \%$, and $13 \%$ of Nigeria university students skipping meals due to lack of time, appetite, and inability to cook, respectively [30]. Fasting/religion and money were mentioned by about $20 \%$ and $15 \%$ of Nigerian University students as a reason for skipping meals, respectively [31]. About half of Saudi Arabia University students skipping meals because they did not feel hunger while one-third of them don't have time and onefifth skip meals because they want to control weight [32]. The study conducted by Shaw revealed that $52 \%$ of adolescent reported lack of time in the morning as the main reason for skipping breakfast [33]. Danquah et al. reported that lack of time, not being hungry, and eating late at night were the reasons behind skipping breakfast in $57 \%, 22 \%$, and $5 \%$ of Ghanaian university students [34]. In the study conducted by Lee and Yoon [35] on Korean University students, the second cause of skipping breakfast after the lack of time (noted by $61 \%$ ) was the habit (17.6\%). A similar study was found with four private university students of Bangladesh, more than 50\% of the respondents skipped their breakfast due to a variety of reasons including class pressure and had fast food after finishing their classes [36].

\section{Impact of Skipping Breakfast on Subjective Appetite}

High protein breakfast consists of $50 \%$ protein, $30 \%$ carbohydrate, and $20 \%$ fat reported to have more benefits on mood, alertness, and attention. This might be attributed to that high-protein breakfast resulted in more stable glucose and insulin than adequate protein breakfast [37]. It was also stated that protein keeps blood sugar levels while carbohydrate is important to offer energy to the body $[38,39]$. Worldwide, there is a common thought that missing breakfast causing an increase in the desire 
for food, which stimulating overeating at following meals and inducing weight gain [10]. Subjective appetite variables such as "sensations of hunger, desire to eat, and prospective consumption" are estimated as higher in breakfast skipping comparing with breakfast eating conditions. Studies show that lunch intake was higher after breakfast skipping [40-43]. During 2015, two studies conducted by Clayton et al. $[44,45]$ where the breakfast representing 25\% energy supplies was taken at 08:00 clock, and lunch and dinner meals at 12:30 and 18:0019:00 clock, respectively. A similar response was noted when standardized lunch (with $35 \%$ of energy requirements) and dinner (with $40 \%$ of energy supplies) meals were delivered so maintaining the energy shortage produced by breakfast skipping. These findings revealed that the inaccurate regulation of subjective appetite is a result of an energy deficit. However, it should be noted that subjective appetite sensibilities do not constantly portend following energy assimilation [46], [47].

\section{Effect of Breakfast Skipping on Appetite- Modulation Peripheral Hormones}

Part of the organization of appetite included numerous intestines peptides and among them the appetite motivator hormone ghrelin as well as hormones linked with satiation and satiety, like "peptide YY (PYY), glucagon-like peptide-1 (GLP-1), glucose-dependent insulinotropic polypeptide, cholecystokinin, and leptin." Recognition of the reaction of such hormones to energy stability inconstancy could deliver worthy data about nutritional interferences (e.g., breakfast skipping) will be acceptable out of the laboratory atmosphere [48]. Astbury et al. [39] reported that the orexigenic hormones, GLP-1 and PYY were superior up to 30 minutes after consuming a 1,050 kJ liquefied meal two and half hours later to breakfast intake, comparing with later to breakfast skipping. Yet, no variations in the orexigenic hormone ghrelin were reported. Also, missing breakfast led to an increase in glucose and insulin as a result of the liquefied meal, compared with breakfast eating. This inhibition of glycemic reaction to the second meal of the day, recognized as the "second meal effect" which linked to glycogen storing [49]. In consistent, Gonzalez et al. [50] reported a trend in increasing glucose and insulin response to a 1,500 kJ liquescent meal ate 3 hours later to skipping, comparing with eating breakfast, even that active GLP-1 levels didn't not diverse between experiments.

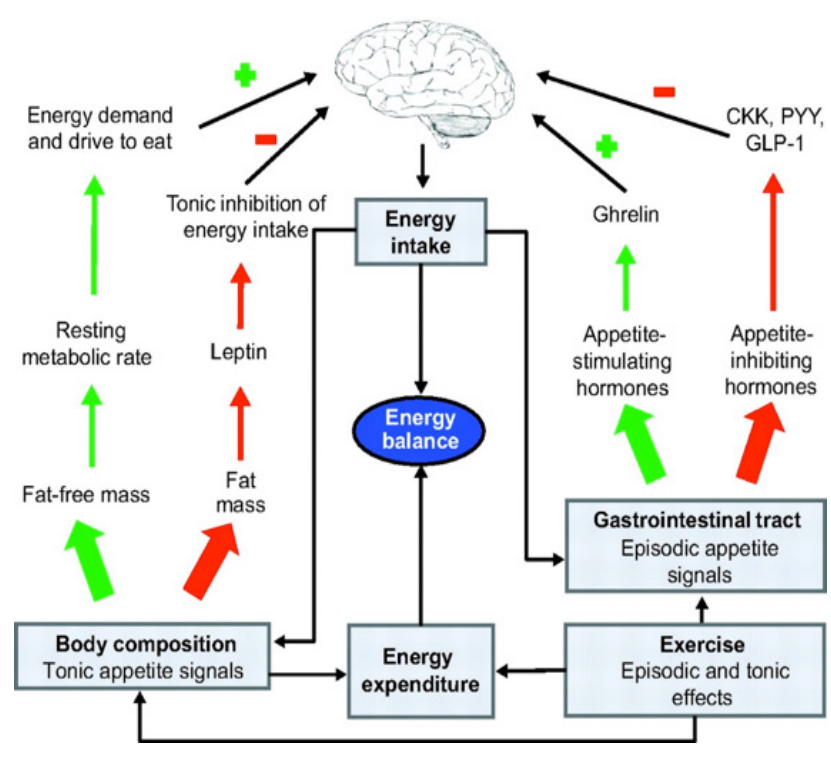

Figure: Peripheral Mechanism of Appetite Regulation

\section{Breakfast Skipping and Obesity}

Skipping breakfast had a greater influence on both waist circumference and BMI than eating dinner more than 3 hours before sleep [51]. An ethnic study shows correlation of overweight and obesity in school-going Fijian adolescent girls [52]. A strong and conguous relationship between breakfast skipping and obesity, but not overweight, reported among children in southeastern European population [53]. Breakfast Skipping is associated with the Risk of Obesity in School-aged Children [54]. Surprisingly, in lean people, skipping breakfast for 6 weeks increased the activity of genes that helped them to burn fat but this effect was not seen in obese adults [55]. A positive association between skipping breakfast, overweight and obesity is globally observed regardless of cultural diversity [56]. Eating of breakfast in all populations may be beneficial. Huang et.al [57] also supported with the potential role of breakfast eating in obesity prevention. Obesity and heart disease claimed in a recent study showing that those who skipped breakfast increased their chance for hardening or narrowing their heart's arteries [58]. Gender may play a key part in breakfast skipping behaviors. In males, breakfast skipping was associated with increased odds of being overweight/obese [59]. 


\section{Breakfast Skipping and Cardiac Complexities}

Habitual avoidance found to be associated with increased risk for development of CAD and hypertension in Western India [60]. Among adults, skipping meals may be linked to excess bodyweight, hypertension, insulin resistance, and elevated fasting lipid concentrations. Men who skipped breakfast had nearly $30 \%$ higher risk of CHD as compared with men who did not [61]. A relationship study between skipping breakfast and CVD risk factors such as blood pressure, serum lipids, smoking, and lock of exercise shows equivalent nature to lack of exercise, smoking, high blood pressure, and high serum total cholesterol [62]. More interestingly, a study in Brazil reflects Skipping breakfast is related to cardiovascular risk factors in adolescents, and this relationship was mainly mediated by trunk fatness [63]. However cardiovascular risk was found to associated with both skipping breakfast and late dinner [1]. Also, commendatory changes in cardiovascular risk factors have been reported by regular Korean traditional diet for $12 \mathrm{wk}$ in hypertensive and diabetic patients [64].

\section{Diabetes and Breakfast}

Skipping breakfast may increase the risk of T2DM independent of lifestyles and baseline levels of BMI and FBG in middle aged male and female, as reported by Uemura et.al [65]. An IRB approved study by Harvard School of Public Health (Boston, MA) reveals an increased risk of T2D in men even after adjustment for BMI [66]. A lower risk of type 2 diabetes mellitus (T2DM) and metabolic syndrome, prompting interest in the influence of breakfast on carbohydrate metabolism and indicators of T2DM risk [67]. The Health Professionals Follow-Up Study, The Nurses' Health Study, a Japanese study and the German EPIC cohort provide evidence that regular healthy breakfast consumption is associated with improved glycemic control [65], [68-70]. Skipping breakfast was closely associated with annual changes in BMI and WC among men, and eating breakfast more than four times per week may prevent the excessive body weight gain associated with skipping breakfast [71]. Also, development of metabolic inflexibility reported in response to prolonged fasting that may in the long-term lead to low-grade inflammation and impaired glucose homeostasis [72].

\section{Altered Cognitive Functions}

Skipping breakfast or eating a low-quality breakfast have a negative effect on cognitive function [73]. Glucose is the main fuel for brain function, and optimal cognitive function requires the maintenance of a stable blood glucose level [74]. Breakfast has a direct effect on blood glucose levels and, in turn, blood glucose levels have a direct effect on cognitive function [75, 76]. In general, the brain performs best when the blood glucose level is in the range of $80-120 \mathrm{mg} / \mathrm{dL}$ [77]. With the gradual depletion of blood glucose and, consequently, energy consumption, people begin to feel hunger and fatigue and experience a decline in cognitive function [78]. A number of studies have reported that skipping breakfast lowers cognitive function and work efficiency [79-81].

\section{Mood Swing and Performance}

Psychological state and mood, all these variables can also be positively influenced by following healthy dietary practices and it is widely believed that one such practice is the regular consumption of breakfast [82]. Breakfast skipping has been considered an important determinant of an unhealthy lifestyle including alcohol use, smoking, and sedentary lifestyle, as well as low educational attainment, mood changes, and depressive symptoms [83]. Rate of depression has increased recently and association between the frequency of eating breakfast and depression in adults found in a recent study. Lack of breakfast consumption is also associated with depression among adults with different socioeconomic factors [84]. Children who habitually consume breakfast are more likely to have favorable nutrient intakes including higher intake of dietary fiber, total carbohydrate and lower total fat and cholesterol. Beneficial effects reported by Katie et.al, of breakfast for on-task behavior in the classroom, mainly in younger children $<13$ years [85]. On the other hand, skipping breakfast and taking meals irregularly were associated with the prevalence of fatigue in medical students [86].

\section{Low Cortisol and Women's' Health}

Women would rather do their hair than start the day with some breakfast, says a new survey. Female breakfast skippers display a disrupted cortisol rhythm and elevated blood pressure [87]. Habitual breakfast skippers would display a similar pattern 
of circulating cortisol and alterations in meal and stress-induced cortisol reactions. Based on a national survey, approximately $25 \%$ of American adults skip breakfast. Skipping breakfast adversely affects menstrual disorders as reported in 2 different studies in young college students of Japan and Palestine [88-90]. Women from developed countries are 2-4 times more likely to have IBS than men [91, 92]. A study in Japan shows fasting (1-2 L of fluid each day, along with some nutrition through their vein) improves pain, discomfort, abdominal distension, diarrhea, anorexia, nausea and anxiety in IBS [93]. But breakfast is strictly recommended along with regular meal pattern in patients with IBS-C because it stimulates colon and increase bowel movement [94, 95]. However, two out of five women admit missing breakfast leaves them hungry mid-morning, nearly $30 \%$ report feeling tired and low in energy and 15 per cent find it hard to concentrate. One in three skip meal in order to get ready for the day [96]. A thinning hair is reported in Reader's Digest [97]. Teens that skip breakfast are almost twice as likely to have bad breath; more than $35 \%$ suffered with bad breath reported in International Journal of Dental Hygiene [98].

\section{Abdominal Discomfort, Ulceration and Cancer}

A Mexican study found association of skipping breakfast with gastric cancer [99] which is third most common cancer in men and the fifth in women. Frequent deviation in meal timing over a prolonged period appears associated with increased risk of developing HP infection and gastritis [100]. Skipping meals, leaving the stomach empty except for stomach acid, can create feelings of nausea [101].

\section{CONCLUSION}

Not only breakfast, skipping a meal often creates harm to health, although fasting has its own advantage which is ritual in many religions. A healthy breakfast but not a heavy breakfast is highly recommended. Those who are in a rush can take a protein rich low volume diet. Protein shake as an alternative for breakfast is a common practice in many western countries but this discussion is not within the scope of this article. Skipping meal in IBS and gastroenteritis may found little benefit but no study ever pointed to skip a breakfast for those issues. A healthy breakfast is different for different people based on age, sex, living style and physical activities. School/University going students should never miss a breakfast causes they badly need a jumpstart of energy for the day. Diabetic people should keep in mind that the same is important for them to sensitize insulin release. Rich or poor, young or elderly, all must have a healthy refreshment in the morning for an energized and enthusiastic day start.

\section{ree REFERENCES CQm}

[1] Zilberter T, Zilberter EY. Breakfast: to skip or not to skip. Front Public Health 2014; 2: 59. doi:10.3389/ fpubh .2014.00059

[2] Timlin MT, Pereira MA. Breakfast frequency and quality in the etiology of adult obesity and chronic diseases. Nutr Rev 2007; 65: 268-81.

[3] Marangoni F, Poli A, Agostoni C, et al. A consensus document on the role of breakfast in the attainment and maintenance of health and wellness. Acta Biomed 2009; 80: 166-71.

[4] Chen J, Cheng J, Liu Y, Tang Y, Sun X, Wang T. Association between breakfast eating habits and health-promoting lifestyle, suboptimal health status in Southern China: a population based, cross sectional study. J Transl Med 2014; 12: 348. doi:10.1186/ s1296 7-014-0348-1

[5] Cho S, Dietrich M, Brown CJP, et al. The effect of breakfast type on total daily energy intake and body mass index: results from the Third National Health and Nutrition Examination Survey (NHANES III). J Am Coll Nutr 2003; 22: 296-302.

[6] Purslow LR, Sandhu MS, Forouhi N, et al. Energy intake at breakfast and weight change: prospective study of 6,764 middle-aged men and women. Am J Epidemiol 2008; 167: 188-92.
[7] Mekary RA, Giovannucci E, Willett WC, et al. Eating patterns and type 2 diabetes risk in men: breakfast omission, eating frequenCy, and snacking. Am J Clin Nutr 2012; 95: 1182-9.

[8] Deshmukh-Taskar PR, Nicklas TA, O'Neil CE, et al. The relationship of breakfast skipping and type of breakfast consumption with nutrient intake and weight status in children and adolescents: the National Health and Nutrition Examination Survey 1999-2006. J Am Diet Assoc 2010; 110(6): 869-78.

[9] Smith KJ, Gall SL, McNaughton SA, Blizzard L, et al. Skipping breakfast: longitudinal associations with cardiometabolic risk factors in the Childhood Determinants of Adult Health Study. Am J Clin Nutr 2010; 92(6): 1316-25.

[10] Pereira MA, Erickson E, McKee P, et al. Breakfast frequency and quality may affect glycemia and appetite in adults and children. J Nutr 2011; 141: 163-8.

[11] Haupt A. Food and Mood: 6 Ways Your Diet Affects How You Feel. Health 2011; Usnews. Available via https://health.usnews.com/health-news/diet-fitness/diet/articles/2011/08/31/ food-and-mood-6-ways-your-diet-affects-how-you-feel

[12] Moschiano F, Messina P, D'Amico D, et al. Headache, eating and 
sleeping behaviors and lifestyle factors in preadolescents and adolescents: preliminary results from an Italian population study. Neurol Sci 2012; 33: 87-90. doi:10.1007/s1007 2-012-1048-3

[13] O'Neil CE, Byrd-Bredbenner C, Hayes D, et al. The role of break fast in health: definition and criteria for a quality breakfast. J Acad Nutr Diet 2014; 114 Suppl 12: S8-26.

[14] Berry MK, Russo A, Wishart JM, et al. Effect of solid meal on gastric emptying of, and glycemic and cardiovascular responses to, liquid glucose in older subjects. Am J Physiol 2002; 284: G655-62.

[15] Betts JA, Chowdhury EA, Javier T, et al. Conference on 'Roles of sleep and circadian rhythms in the origin and nutritional management of obesity and metabolic disease' Cuthbertson Medal Lecture. Is breakfast the most important meal of the day? Proc Nutr Soc 2016; 75: 464-74.

[16] de Castro JM. Accommodation of particular foods or beverages into spontaneously ingested evening meals. Appetite 1994; 23: 57-66.

[17] Betts JA, Thompson D, Richardson JD, et al. Bath Breakfast Project (BBP) - examining the role of extended daily fasting in human energy balance and associated health outcomes: study protocol for a randomised controlled trial [ISRCTN31521726]. Trials 2011; 12: 172-84.

[18] Ruge T, Hodson L, Cheeseman J, et al. Fasted to fed trafficking of Fatty acids in human adipose tissue reveals a novel regulatory step for enhanced fat storage. J Clin Endocrinol Metab 2009; 94: 1781-8.

[19] Dubois L, Girard M, Kent MP, et al. Breakfast skipping is associated with differences in meal patterns, macronutrient intakes and overweight among pre-school children. Public Health Nutr 2009; 12(01): 19-28.

[20] Silliman K, Rodas-Fortier K, Neyman M. A survey of dietary and exercise habits and perceived barriers to following a healthy lifestyle in a college population. Cal J Health Promot 2004; 18: 281.

[21] Sakamaki R, Toyama K, Amamoto R, et al. Nutritional knowledge, food habits and health attitude of Chinese university students-a cross sectional study-. Nutr J 2005; 4(1): 1.

[22] Gross SM, Bronner Y, Welch C, et al. Breakfast and lunch meal skipping patterns among fourth grade children from selected public schools in urban, suburban, and rural Maryland. J Am Diet Assoc 2004; 104(3): 420-3.

[23] Savige G, MacFarlane A, Ball K, et al. Snacking behaviours of adolescents and their association with skipping meals. Int J Behav Nutr Phys Act 2007; 4(1): 36.

[24] De Bate RD, Topping M, Sargent RG. Racial and gender differences in weight status and dietary practices among college students. Adolescence 2001; 36(144): 819.

[25] Australian Bureau of Statistics. Australian Health Survey: Nutrition First Results-Foods and Nutrients, 2011-12. Australian Government, Canberra, Australia, 2014.

[26] Pendergast FJ, Livingstone KM, Worsley A, et al. Correlates of meal skipping in young adults: a systematic review. Int J Behav Nutr Phys Act 2016; 13: 125.

[27] Mulye TP, Park MJ, Nelson CD, et al. Trends in adolescent and young adult health in the United States. J Adolesc Health 2009; 45(1): 8-24.

[28] Betts NM, Amos RJ, Keim K, et al. Ways young adults view foods. J Nutr Educ 1997; 29(2): 73-9.

[29] Jabs J, Devine CM. Time scarcity and food choices: an overview. Appetite 2006; 47(2): 196-204.

[30] Afolabi W, Towobola SK, Oguntona CR, et al. Pattern of fast food consumption and contribution to nutrient intakes of Nigerian University students. Int J Educ Res 2013; 1(5): 1-10.

[31] Ukegbu PO, Uwaegbute AC, Usonka VA. Contribution of snacks to energy and nutrient intake of undergraduates in a Nigerian university. Malaysian J Nutr 2015; 21(1): 15-23.

[32] Eldisoky ST. Interactive relation between dietary habits and spread of malnutrition diseases. Ann Agric Sci (Cairo) 2003; 48(2): 663-75.

[33] Shaw ME. Adolescent breakfast skipping: an Australian study. Adolescence 1998; 33(132): 851-61.

[34] Danquah AO, Odjoji Y, Graham-Acquaah S, et al. A pilot study of the dietary and physical activity behaviours of international students: implications for health promotion. Afr J Food Sci 2010; 4(3): 86-92.

[35] Yao CZ, Shun ML, Guo LX, et al. Influences of protein to energy ratios in breakfast on mood, alertness and attention in the healthy undergraduate students. Health 2011; 3: 383-93. doi:10.4236/ health.2011.36065

[36] Gannon MC, Nuttall FQ. Control of blood glucose in type 2 diabetes without weight loss by modification of diet composition. Nutr Metab (Lond) 2006; 3: 16.

[37] Munmun SB, Shatabdi G. Fast food preferences and food habits among students of private universities in Bangladesh. South East Asia Journal of Public Health 2013; 3(1): 61-64.

[38] Austin GL, Ogden LG, Hill JO. Trends in carbohydrate, fat, and protein intakes and association with energy intake in normal-weight, overweight, and obese individuals: 1971-2006. Am J Clin Nutr 2011; 93(4): 836-43. doi:10.3945/ajcn.110.000141 [Epub $2011 \mathrm{Feb} 10]$

[39] Astbury NM, Taylor MA, Macdonald IA. Breakfast consumption affects appetite, energy intake, and the metabolic and endocrine responses to foods consumed later in the day in male habitual breakfast eaters. J Nutr 2011; 141(7): 1381-9.

[40] Leidy HJ, Ortinau LC, Douglas SM, Hoertel HA. Beneficial effects of a higher-protein breakfast on the appetitive, hormonal, and neural signals controlling energy intake regulation in overweight/ obese, "breakfast-skipping," late-adolescent girls. Am J Clin Nutr 2013; 97(4): 677-88. doi:10.3945/ ajcn.112.053116

[41] Levitsky DA, Pacanowski CR. Effect of skipping breakfast on subsequent energy intake. Physiol Behav 2013; 119: 9-16. doi:10.1016/j.physbeh.2013.05.006

[42] McCrory MA. Meal skipping and variables related to energy balance in adults: a brief review, with emphasis on the breakfast meal. Physiol Behav 2014; 134: 51-4.

[43] Flint A, Raben A, Blundell JE, et al. Reproducibility, power and validity of visual analogue scales in assessment of appetite sensations in single test meal studies. Int J Obes 2000; $24: 38-48$.

[44] Clayton DJ, Barutcu A, Machin C, et al. Effect of breakfast omission on energy intake and evening exercise performance. Med Sci Sports Exerc 2015a; 47: 2645-52.

[45] Clayton DJ, Stensel DJ, James LJ. Effect of breakfast omission on subjective appetite, metabolism, acylated ghrelin and GLP-1736 during rest and exercise. Nutrition 2016; 32(2): 179-85.

[46] Clayton DJ, Stensel DJ, Watson P, et al. The effect of post-exercise drink macronutrient content on appetite and energy intake. Appetite 2014; 82: 173-9.

[47] James LJ, Funnell MP, Milner S. An afternoon snack of berries reduces subsequent energy intake compared to an isoenergetic confectionary snack. Appetite 2015; 95: 132-7.

[48] Clayton DJ, James LJ. The effect of breakfast on appetite 
regulation, energy balance and exercise performance. Proc Nutr Soc 2016; 75(3): 319-27. doi:10.1017/S0029665115004243

[49] Jovanovic A, Leverton E, Solanky B, et al. The second meal phenomenon is associated with enhanced muscle glycogen storage in humans. Clin Sci 2009; 117: 119-27.

[50] Gonzalez JT, Veasey RC, Rumbold PLS, et al. Breakfast and exercise contingently affect postprandial metabolism and energy balance in physically active males. Br J Nutr 2013; 110: 721-32.

[51] Yoko W, Isao S, Henmi I et al. Skipping Breakfast is Correlated with Obesity. J Rural Med. 2014; 9(2): 51-58. doi: [10.2185/jrm.2887] PMID: 25648986

[52] Thompson-McCormick JJ, Thomas JJ, Bainivualiku A, et al. Breakfast skipping as a risk correlate of overweight and obesity in school-going ethnic Fijian adolescent girls. Asia Pac J Clin Nutr. Asia Pac J Clin Nutr. 2010; 19(3): 372-382. PMID: 20805082

[53] Burazeri G, Hyska J, Mone I, et al. Breakfast Skipping Is an Independent Predictor of Obesity but not Overweight Among Children in a Southeastern European Population. Int J Vitam Nutr Res. 2016 Jun;86(3-4): 242-248. PMID: 28806888. doi: 10.1024/0300-9831/a000272

[54] Isgin K, Bellikci-Koyu E, Ajyol-Mutlu A, et al. Breakfast Skipping Linked to the Risk of Obesity in School-aged Children. Journal of the academy of Nutrition and Dietetics September. 2017; 117(9): page A19. doi: https://doi.org/10.1016/j.jand.2017.06.352

[55] Ana S. The effects of skipping breakfast depend on your weight MedicalNewsToday. 29 November 2017, Powered by TrendMD.

[56] Horikawa C, Kodama S, Yachi Y, et al. Skipping breakfast and prevalence of overweight and obesity in Asian and Pacific regions: A meta-analysis. Prev Med. 2011; 53(4-5): 260-267.https:// doi.org/10.1016/j.ypmed.2011.08.030

[57] Huang C, Hu H, Fan Y, et al. Associations of breakfast skipping with obesity and health-related quality of life: evidence from a national survey in Taiwan. Int J Obes. 2010; 34: 720-725.

[58] [58] Danielle Z. Skipping breakfast to lose weight can INCREASE the risk of obesity and heart disease, a study claims. Dailymail. co.uk 2 October 2017.

[59] [59] Barrett N, Riordan F, Michels N, et al. Breakfast Skipping and overweight/obesity among European adolescents, a cross-sectional analysis of the HELENA dataset: a DEDIPAC study. [version 1; referees: 1 approved with reservations]. HRB Open Res 2018, 1:19. https://doi.org/10.12688/hrbopenres.12847.1

[60] [60] Sharma K, Shah K, Brahmbhatt P, et al. Skipping breakfast and the risk of coronary artery disease. QJM. 2018;111(10): 715 719. doi: 10.1093/qjmed/hcy162. PMID: 30016512

[61] [61] Cahill LE, Chiuve SE, Mekary RA,. Prospective Study of Breakfast Eating and Incident Coronary Heart Disease in a Cohort of Male U.S. Health Professionals. Circulation. 2013; 128(4): 337343. doi:10.1161/CIRCULATIONAHA.113.001474. PMID: 23877060

[62] [62] Sakata K, Matumura Y, Yoshimura N, et al. Relationship between skipping breakfast and cardiovascular disease risk factors in the national nutrition survey data. Nihon Koshu Eisei Zasshi. 2001; 48(10): 837-41. PMID:11725527

[63] [63] Cayres SU, Júnior IF, Barbosa MF, et al. Breakfast frequency, adiposity, and cardiovascular risk factors as markers in adolescents. Cardiol Young. 2016; 26(2): 244-9. doi:10.1017/ S1047951115000050. Epub 2015 Feb 10. PMID: 25668394

[64] Jung SJ, Park SH, Choi EK, et al. Beneficial effects of Korean traditional diets in hypertensive and type 2 diabetic patients. J Med Food. 2014; 17(1): 161-71. PMID: 24456367. doi:10.1089/ jmf.2013.3042
[65] Uemura M1, Yatsuya $\mathrm{H}$, Hilawe EH, et al. Breakfast Skipping is Positively Associated With Incidence of Type 2 Diabetes Mellitus: Evidence From the Aichi Workers' Cohort Study. J Epidemiol. 2015; 25(5): 351-358. doi:10.2188/jea.JE20140109. PMID: 25787236

[66] Mekary RA, Giovannucci E, Willett WC, et al. Eating patterns and type 2 diabetes risk in men: breakfast omission, eating frequency, and snacking. Am J Clin Nutr. 2012; 95(5): 1182-1189. doi:10.3945/ajcn.111.028209. PMID: 22456660

[67] Maki KC, Phillips-Eakley AK, Smith KN. The Effects of Breakfast Consumption and Composition on Metabolic Wellness with a Focus on Carbohydrate Metabolism. Adv Nutr. 2016; 7(3): 613S-621S. doi:10.3945/an.115.010314. PMID: 27184288

[68] Iqbal K, Schwingshackl L, Gottschald M, et al. Breakfast quality and cardiometabolic risk profiles in an upper middle-aged German population. Eur. J. Clin. Nutr. 2017; 71: 1312-1320. doi:10.1038/ejcn.2017.116

[69] Mekary RA, Giovannucci E, Cahill L, et al. Eating patterns and type 2 diabetes risk in older women: Breakfast consumption and eating frequency. Am. J. Clin. Nutr. 2013; 98: 436-443. doi:10.3945/ ajcn.112.057521

[70] Mekary RA, Giovannucci E, Willett WC, et al. Eating patterns and type 2 diabetes risk in men: Breakfast omission, eating frequency, and snacking. Am. J. Clin. Nutr. 2012; 95: 1182-1189. doi:10.3945/ ajcn.111.028209.

[71] Sakurai M, Yoshita M. Skipping breakfast and 5-year changes in body mass index and waist circumference in Japanese men and women. Obes Sci Pract. 2017; 3(2): 162-170. doi:10.1002/osp4.106. PMID: 2870221

[72] Nas A, Mirza N, Hägele F, et al. Impact of breakfast skipping compared with dinner skipping on regulation of energy balance and metabolic risk. Am J Clin Nutr. 2017; 105(6): 1351-1361. doi:10.3945/ajcn.116.151332. PMID: 28490511

[73] Hoyland A, Dye L, Lawton CL. A systematic review of the effect of breakfast on the cognitive performance of children and adolescents. Nutr Res Rev. 2009; 22(2): 220-243. doi:10.1017/ S0954422409990175

[74] Sunram-Lea Sl, Foster JK, Durlach P, et al. The effect of retrograde and anterograde glucose administration on memory performance in healthy young adults. Behav Brain Res. 2002; 134(12): 505-516. doi:10.1016/S0166-4328(02)00086-4

[75] Scholey AB, Harper S, Kennedy DO. Cognitive demand and blood glucose. Physiol Behav. 2001; 73(4): 585-592. doi:10.1016/ S0031-9384(01)00476-0

[76] Messier C. Glucose improvement of memory: a review. Eur J Pharmacol. 2004; 490(1-3): 33-57. doi:10.1016/j. ejphar.2004.02.043

[77] Morohoshi E, Adachi S. Effect of the different types of interventions on meal aimed to control the postprandial blood glucose levels: profiles of young healthy women monitored by the self measuring method. J Jpn Health Med Assoc. 2015; 23: 279-288

[78] Kennedy DO, Scholey AB. Glucose administration, heart rate and cognitive performance: effects of increasing mental effort. Psychopharmacology (Berl). 2000; 149(1): 63-71. doi:10.1007/ s002139900335

[79] Veasey RC, Gonzalez JT, Kennedy DO, et al. Breakfast consump tion and exercise interact to affect appetite, cognitive performance and mood later in the day. Appetite. 2012; 59(2): 636-641. doi:10.1016/j.appet.2012.05.103

[80] Wesnes KA, Pincock C, Richardson D, et al. Breakfast reduces declines in attention and memory over the morning in 
schoolchildren. Appetite. 2003; 41(3): 329-331. doi:10.1016/j. appet.2003.08.009

[81] Hoyland A, Lawton C, Dye L. Influence of breakfast on cognitive performance, appetite and mood in healthy young adults. Appetite. 2008; 50(2): 560-566. doi:10.1016/j.appet.2007.09.036.

[82] Veasey RC, Haskell-Ramsay CF, Kennedy DO. The Effect of Breakfast Prior to Morning Exercise on Cognitive Performance, Mood and Appetite Later in the Day in Habitually Active Women. Nutrients. 2015; 7(7): 5712-5732. doi:10.3390/nu7075250. PMID: 26184302

[83] Keski-Rahkonen A., Kaprio J., Rissanen A., et al. Breakfast skipping and health-compromising behaviors in adolescents and adults. Eur. J. Clin. Nutr. 2003; 57: 842. doi:10.1038/sj.ejcn.1601618

[84] Lee SA, Park EC, Ju YJ, et al. Breakfast consumption and depressive mood: A focus on socioeconomic status. Appetite. 2017; 114: 313-319. doi:10.1016/j.appet.2017.04.007. Epub 2017 Apr 8. PMID: 28400301

[85] Katie A, Lawton CL, Louise D. The effects of breakfast on behavior and academic performance in children and adolescents. Front Hum Neurosci. 2013; 7: 425. doi:10.3389/fnhum.2013.00425. PMID: 23964220

[86] Tanaka M, Mizuno K, Fukuda S, et al. Relationships between dietary habits and the prevalence of fatigue in medical students. Nutrition. 2008; 24(10): 985-9. doi: 10.1016/j.nut.2008.05.003. Epub 2008 Jun 17. PMID: 18562170

[87] Witbracht M, Keim NL, et al. Female breakfast skippers display a disrupted cortisol rhythm and elevated blood pressure. Physiol Behav. 2015; 140: 215-21. doi:10.1016/j.physbeh.2014.12.044. Epub 2014 Dec 27. PMID: 25545767

[88] Helwa HAA, Mitaeb AA. Prevalence of dysmenorrhea and predictors of its pain intensity among Palestinian female university students. BMC Womens Health. 2018; 18: 18. doi:10.1186/s12905018-0516-1. PMID: 29334974

[89] Fujiwara T. Skipping breakfast is associated with dysmenorrhea in young women in Japan. Int J Food Sci Nutr. 2003; 54(6): 505-9. PMID:14522696. doi:10.1080/09637480310001622369

[90] Fujiwara T, Sato N, Awaji H, et al. Skipping breakfast adversely affects menstrual disorders in young college students. Int J Food Sci Nutr. 2009; 60 Suppl 6: 23-31. PMID: 19468949

\section{doi:10.1080/09637480802260998}

[91] Choung RS, Locke GR. Epidemiology of IBS. Gastroenterol Clin North Am. 2011; 40: 1-10.

[92] Chang L, Heitkemper MM. Gender differences in irritable bowel syndrome. Gastroenterology. 2002; 123: 1686-1701.

[93] Kanazawa M, Fukudo S. Effects of fasting therapy on irritable bowel syndrome. Int J Behav Med. 2006; 13(3): 214-20. PMID: 17078771. doi:10.1207/s15327558ijbm1303_4

[94] McKenzie YA, Bowyer RK, Leach H, et al. British Dietetic Association systematic review and evidence-based practice guidelines for the dietary management of irritable bowel syndrome in adults (2016 update). J Hum Nutr Diet. 2016; 29: 549-575.

[95] National Institute for Health and Clinical Excellence. Irritable bowel syndrome in adults: diagnosis and management. Clinical Guideline [CG61]. Published: February 2008. Last updated: February 2015. Cited 2017-01-03. URL: https://www. nice.org.uk/guidance/cg61/resources/irritable-bowel-syndrome-in-adults-diagnosis-and-management-975562917829.

[96] Jenny $\mathrm{H}$. Women would rather do their hair than eat breakfast: One in three skip meal in order to get ready for the day dailymail. co.uk 25 January 2014

[97] Weinhouse B. Beauty 18 Bad Habits That Are Thinning Your Hair. Reader's Digest URL: https://www.rd.com/health/beauty/ bad-habits-that-cause-thinning-hair/

[98] Rani H, Ueno M, Zaitsu T, et al. 'Oral malodour among adolescents and its association with health behaviour and oral health status', Int J Dent Hyg, 2016; 14(2): 135-41. doi: 10.1111/idh.12160.

[99] Verdalet-Olmedo M, Sampieri CL, Morales-Romero J, et al. Omission of breakfast and risk of gastric cancer in Mexico. World J Gastrointest Oncol. 2012; 4(11): 223-229. doi:10.4251/wjgo. v4.i11.223. PMID: 23444276

[100] Lim SL, Canavarro C, Zaw MH et al. Irregular Meal Timing Is Associated with Helicobacter pylori Infection and Gastritis. ISRN Nutr. 2012; 2013: 714970. doi:10.5402/2013/714970. PMID: 24967249

[101] Cindy H. Skipping Meals \& Stomach Cramps. www.livestrong. com Aug. 14, 2017. 